\title{
Comprehensive Evaluation of the Toxicity of the Flame Retardant (decabromodiphenyl ether) in a Bioindicator Fish (Gambusia affinis)
}

Juan Manuel Pérez Iglesias ( $\square$ juanmapi@gmail.com )

Universidad Nacional de San Luis https://orcid.org/0000-0003-1399-4107

Patricia Silvia Gonzalez

UNSL: Universidad Nacional de San Luis

Mirian Roxana Calderon

UNSL: Universidad Nacional de San Luis

Guillermo Sebastian Natale

UNLP: Universidad Nacional de la Plata

Cesar Americo Almeida

UNSL: Universidad Nacional de San Luis

\section{Research Article}

Keywords: biomarkers integration, cytotoxicity, emerging contaminants, flame retardants, Gambusia affinis, oxydative damage, neurotoxicity

Posted Date: May 24th, 2021

DOl: https://doi.org/10.21203/rs.3.rs-500736/v1

License: (c) (1) This work is licensed under a Creative Commons Attribution 4.0 International License. Read Full License 


\section{Abstract}

In recent years, polybrominated diphenyl ethers or PBDE have been identified as the new emerging pollutants. These pollutants are derived from e-waste and their adverse effect on biota has been proven. In this work, the adverse effects of BDE-209 on mosquitofish (Gambusia affinis) were evaluated. Acute toxicity bioassays were carried out with daily renewal of solutions, using different concentrations of environmental relevance ranged between 10 and $100 \mu \mathrm{g} \cdot \mathrm{L}^{-1}$ of BDE-209. After 48 and $96 \mathrm{~h}$ of exposure, mortality, individual activity (swimming), biochemical activity (catalase; thiobarbituric acid reactive substances; and acetylcholinesterase), and cytotoxic responses (micronucleus frequencies) were studied. In addition, integrated biomarker response and multivariate analyses were conducted to study the correlation of biomarkers. The calculated lethal concentrations 50 remained constant after all exposure times $\left(24\right.$ to $96 \mathrm{~h}$ ), and the corresponding value was $27.79 \mu \mathrm{g} . \mathrm{L}^{-1}$ BDE-209. Furthermore, BDE-209 induced effects on the swimming activity of this species in relation to acetylcholine, since BDE-209 increased, produced oxidative damage at the biochemical level and genotoxicity after $48 \mathrm{~h}$ of sublethal concentrations (10 and $25 \mu \mathrm{g} . \mathrm{L}^{-1}$ BDE-209) of exposure. The results show that BDE-209 has biochemical, cytotoxic, neurotoxic and genotoxic potential on $G$. affinis. In addition, mosquitofish can be used as a good bioindicator to evaluate environmental stressors and flame retardants could be a risk factor to Neotropical species.

\section{Introduction}

Polybrominated diphenyl ethers (PBDE), a class of brominated flame retardants, are chemical compounds incorporated in different materials (e.g. electronic components) used to reduce their flammability (Cordero et al. 2004; EFSA 2011; Santín et al. 2013; McGrath et al. 2017; Anacleto et al. 2018). These compounds, also known electronic waste or e-waste, have high lipophilicity enabling substances to bioaccumulate, biomagnify and its quantities of estimated atmospheric emissions reaching 70-700 tonnes total (Ueno et al. 2004; La Guardia et al. 2007; Abbasi et al. 2015; McGrath et al. 2017; Eljarrat and Barceló 2018). Levels of PBDE have been determined in different environments like water, sediment, fishes and other biota samples (Ueno et al. 2004; Peng et al. 2009; Kuo et al. 2010; Wang et al. 2011; Barón et al. 2013; Santín et al. 2013; Wu et al. 2013; McGrath et al. 2017; Lee et al. 2020). Reciently, they have been mentioned as the new emerging pollutants, because they are persistent, they bioaccumulate and their high toxicity in living organisms has been proven (Ueno et al. 2004; Cordero et al. 2004; Santín et al. 2013; Anacleto et al. 2018; Liu et al. 2018; Lee et al. 2020). In Latin America, new investigations have been reported the presence of PBDE (Lana et al. 2010; Ondarza et al. 2011; Miglioranza et al. 2013; Tombesi et al. 2016). Particularly, decabromodiphenyl ether (BDE-209) is a fully brominated diphenyl ether compound within the 209 congenera of PBDEs, and is widely distributed in the environment - water and sediments or even wildlife (Tomy et al. 2004; Labandeira et al. 2007; La Guardia et al. 2007; François and Verreault 2018). Recently, it has been found that BDE-209 bioacumulates in several fish species in Lake Michigan (USA) (Kuo et al. 2010) and was detected that these emergent contaminant could be biomagnified in marine trophic chain, reaching tertiary consumers (Hu et al. 2010). 
In ecotoxicology investigations, bioindicators are often used because are organisms that identify longterm interaction of several environmental conditions, and they also react to a sudden change of important combinations of factors (Hamza-Chaffai 2014). A perfect bioindicator to environmental stressor monitoring should have several characteristics, for example: (i) to accumulate a large number of xenobiotics without causing death; (ii) to have enough distribution and quantity to ensure a representative and comparable sample with other sites; (iii) to have relatively long life cycle; (iv) to have a good dose-effect response; ( $v$ ) to be easily sampled and maintained under laboratory conditions, and (vi) to be tested in several endpoints in cells and tissues (Hamza-Chaffai 2014; Newman 2014). Also, in ecotoxicological assessments, biomarkers have been used as an early warning signal, and an adequate tool to detect adverse effects on the environment, being induced by emerging pollutants (Newman 2014). Specifically, cellular and biochemical biomarkers are useful as early warning signs of the exposure to environmental stressors in non-target organisms, since they can detect adverse toxicological effects induced by environmental stressors, before they are irreversible for the organism (Newman 2014; Larramendy 2017).

Combination of biomarkers and bioindicator species can be used as valid tools in laboratory studies, because they simulate real exposure scenarios, considering actual concentrations of these stressors, which can cause oxidative damage, and generate reactive oxygen species (ROS) (Beliaeff and Burgeot 2002; Newman 2014). Specifically, biochemical and cellular biomarkers may determinate the potential of environmental stressors as ROS, assessing alterations in antioxidant enzymes, oxidative DNA damage, and physiological stress responses through toxicokinetics and toxicodynamics studies (Beliaeff and Burgeot 2002; Newman 2014; Larramendy 2017). In addition, cellular biomarkers have been very useful in the study of clastogenic or aneugenics events with the determination of the frequency of micronucleus (MNs). The damages in the DNA of these events can later on trigger mutations or chromosomal aberrations that may have effects at higher levels of biological organization, such as physiological dysfunctions or even cancer (Newman 2014; Larramendy 2017). Nevertheless, the evaluation of a single biomarker in a bioindicator may not be adequate and recently the comprehensive evaluation of biomarkers has been suggested in order to achieve holistic responses that allow detecting signals that prevent irreversible effects on ecosystems (van der Oost et al. 2003; Newman 2014). Therefore, cellular and biochemical biomarkers should be analysed integrally (Adams and Ham 2011; Newman 2014). Consequently, biomonitoring programmes should include biomarkers which measure at molecular, biochemical or cellular levels, to detect whether the organism has been exposed to environmental stressors (Newman 2014; Rautenberg et al. 2015; Paniagua-Michel and Olmos-Soto 2016).

In the last century, the mosquitofish Gambusia affinis has been introduced in many areas worldwide to control mosquito larvae. Furthermore, G. affinis has a broad diet, excellent physiological tolerance, with rapid population growth, genetic variability, adequate dispersal trends and good adaptability to different settings (Rautenberg et al. 2015; Cabrera et al. 2017; Touaylia and Labiadh 2019). Due to these characteristics, the use of $G$. affinis has been suggested as a good bioindicator species to monitor changes at the different biological organization levels and adverse effects on enzymes such as catalase (CAT), acetylcholinesterase (AChE), and thiobarbituric acid-reacting substances (TBARS) after the 
exposure to nanoparticles (Rao et al. 2005; Rautenberg et al. 2015; Dang et al. 2017; Díez-del-Molino et al. 2018; Hou et al. 2018; Touaylia and Labiadh 2019). Added to this, some studies have examined biomarkers and potential adverse effects of BDE-209 in aquatic vertebrates in vivo (Ross et al. 2009; Jin et al. 2010; He et al. 2011; Zhao et al. 2011; Garcia-Reyero et al. 2014; Li et al. 2014; Xie et al. 2014; Yu et al. 2015; Chen et al. 2016; Zhu et al. 2016; Han et al. 2017; Anacleto et al. 2018; Wang et al. 2018; Espinosa Ruiz et al. 2019). Specifically, the adverse effects of BDE-209 previously documented in fishes have been the following: altered energy budget (Anacleto et al. 2018), disruption of the thyroid system (Noyes et al. 2011; Li et al. 2014; Han et al. 2017) alteration in thyroid and reproduction systems (He et al. 2011; Yu et al. 2015), adverse effects on antioxidant systems such as glutathione system, catalase and superoxide dismutase (Zhao et al. 2011; Xie et al. 2014), cholinergic and locomotor system of fish (Goodman 2009; He et al. 2011; Garcia-Reyero et al. 2014; Zhu et al. 2016; Wang et al. 2018), oxidative stress in proteins related to cell cycle (Espinosa Ruiz et al. 2019), cytotoxicity and apoptosis induction and, effects on gene transcriptions (Li et al. 2014).

Although large environmental reservoirs of BDE-209 are being created in sediments, these represent a long-term threat to biota, BDE-209 breaks down into more persistent, more bioaccumulative, more toxic, and more mobile PBDE congeners in the environment (Ross et al. 2009; Hu et al. 2010; Kuo et al. 2010); its adverse effects have been scarcely studied, and in Neotropical regions where its presence is being reported, there are no studies on the impact on biota. Added to this, the studies mentioned above reported effects in isolation, without considering the comprehensive multisystemic or integrative responses that occur when an organism is exposed to this kind of emergent environmental stressor. In this context, this study is aimed at assessing, for the first time, the integral organism response to effects of BDE-209 on the bioindicator species $G$. affinis, species inhabits Neotropical regions.

\section{Materials And Methods}

\subsection{Chemicals}

Methanol, Giemsa stain and $\mathrm{H}_{2} \mathrm{O}_{2}$ were obtained from Biopack Co. Acetylcholine, BHT, DNTB and MDA were purchased from Sigma-Aldrich (Darmstadt, Germany). Decabromodiphenyl ether (BDE-209) was provided by Sigma Aldrich.

\subsection{Chemical analysis}

Quantitative analysis of BDE-209 was carried out by Shimadzu Model 2010 GC-MS equipped with an AOC-20i auto injector (Shimadzu, Japan), using negative chemical ionization ( $\mathrm{NCl}$ ) in the selected ion monitoring (SIM) mode. A CP-Sil $13 \mathrm{CB}(12.5 \mathrm{~m} \times 0.25 \mathrm{~mm}$ i.d., $0.2 \mu \mathrm{m}$ film thickness) capillary column was used. Ion fragments $\mathrm{m} / \mathrm{z} 79,81,486.7$, and 488.7 were monitored for BDE-209, according to the method proposed by Peng et al. (2009). The quantification was performed by external standard method. The limit of quantification was $0.6 \mathrm{ng} \mathrm{L}^{-1}$. 


\subsection{Model organism}

Fish males of Gambusia affinis were obtained from an unpolluted permanent pond located in El Volcán, San Luis Province, Argentina ( $33^{\circ} 15^{\prime} 01^{\prime \prime} \mathrm{S}, 66^{\circ} 11^{\prime} 43^{\prime \prime}$ W) with the authorization of the Ministry of Environment, Agriculture and Production of the province of San Luis ( $\mathrm{N}^{\circ}$ Res. 49-PMA-2019). Mature adults of $G$. affinis were transported and acclimated to the laboratory under controlled conditions (photoperiod 16:8; temperature $25 \pm 1^{\circ} \mathrm{C}$; daily renewed dechlorinated tap water: $\mathrm{pH} 7.12$, conductivity 412 $\mu \mathrm{S} . \mathrm{cm}^{-1}$, hardness $186 \mathrm{mg} . \mathrm{L}^{-1} \mathrm{CaCO}_{3}$, alkalinity $250 \mathrm{mg} \cdot \mathrm{L}^{-1} \mathrm{CaCO}_{3}$, nitrate $0.6 \mathrm{mg} \cdot \mathrm{L}^{-1}$ ) for two weeks before conducting the experiments, according to the protocols of the Institutional Animal Care and Use Committee (CICUA protocol Q-322/19), from National University of San Luis.

\subsection{Ecotoxicity bioassay}

Toxicity tests were performed following standardized methods proposed by the USEPA (2002) with minor modifications for local species (Vera-Candioti et al. 2010). All experiments were conducted putting five individuals per replicate in $1 \mathrm{~L}$ glass jars, with $1 \mathrm{~g} \mathrm{~L}^{-1}$ density of the organisms $(n=15$ per treatment). Negative and positive controls as well as increasing gradient concentrations of BDE-209 with test solutions replaced every $24 \mathrm{~h}$ in acute exposure $(96 \mathrm{~h}$ ) were used. Fishes were starved for $24 \mathrm{~h}$ before initiation of the experiments and were not fed during the bioassays. Bioassays were carried out under controlled conditions such as photoperiod (16:8), daily renewal of the solutions, bioterium temperature $\left(25 \pm 1^{\circ} \mathrm{C}\right)$. Dechlorinated tap water ( $\mathrm{pH} \mathrm{7.12}$; conductivity $412 \mu \mathrm{S} . \mathrm{cm}^{-1}$; hardness $186 \mathrm{mg} \mathrm{CaCO}_{3} \mathrm{~L}^{-1}$; alkalinity $250 \mathrm{mg} \mathrm{CaCO}_{3} \mathrm{~L}^{-1}$; chloride $7.1 \mathrm{mg} . \mathrm{L}^{-1}$; nitrate $0.6 \mathrm{mg} . \mathrm{L}^{-1}$; sulphate; $17 \mathrm{mg} . \mathrm{L}^{-1}$; sodium 21.5 mg.L-1; calcium $54.3 \mathrm{mg} . \mathrm{L}^{-1}$; potassium $1.9 \mathrm{mg} . \mathrm{L}^{-1}$ and magnesium $8.1 \mathrm{mg} . \mathrm{L}^{-1}$ ) was used for the experiments. The BDE-209 sublethal concentrations for fish exposures were selected based on literature according to previous reports in zebrafish model (Garcia-Reyero et al. 2014; Zhu et al. 2016; Han et al. 2017), and considering the environmental relevant concentrations reported on literature (Mackintosh et al. 2015; McGrath et al. 2017). G. affinis were exposed to environmental concentrations equal to $10,25,50$ and $100 \mu \mathrm{g} . \mathrm{L}^{-1}$ of BDE-209, dissolved in methanol. The positive control group was prepared adding methanol $\left(100 \mu \mathrm{g} \cdot \mathrm{L}^{-1}\right)$. The solvent final concentration was the same in all the treatments, always lower than $0.1 \%$ (Kaviraj et al. 2004) All treatments (control and BDE-209 exposed groups) were carried out by triplicate. To evaluate biochemical and cellular biomarkers, fishes were euthanized by dissection at the operculum level, then the blood samples were extracted and biochemically analysed. To evaluate these endpoints, all fishes were anesthetized and sacrificed after 48 and $96 \mathrm{~h}$ of exposure. The same procedures were followed in all the treatments.

\subsection{Biomarkers}

\subsubsection{Cytogenetical endpoints: MNs assays}


Peripheral blood of each fish were smeared onto pre-cleaned slides according to Vera Candioti et al. (2010). Then, slides with blood samples were air dried, fixed with methanol $\left(4^{\circ} \mathrm{C}\right)$, and stained with Giemsa solution (5\%). Finally, the coded slides were quantified. The same researcher carried out all the experiments at microscopy $1000 \times$ magnification. The $\mathrm{MN}$ frequency was determined by analysing a total of 1000 mature erythrocytes, expressed as the total number of MN per 1000 cells (Fenech 2007)

\subsubsection{Biochemical endpoints: CAT, TBARS and AChE activity}

Supernatants from homogenates of whole fish were obtained applying the methodology proposed by Brodeur et al. (2017), with minor modifications. Briefly, post-mitochondrial supernatant was prepared (in ice bath cooling) from a $1 \mathrm{~mL}$ homogenate of fish tissues with a buffer Tris $50 \mathrm{mM}(\mathrm{pH} 7.4)$ containing 1 $\mathrm{mM}$ EDTA and sucrose $0.25 \mathrm{M}$. The homogenate was centrifuged at $110^{4} \times \mathrm{g}$ for $10 \mathrm{~min}$ at $4^{\circ} \mathrm{C}$. The supernatant was used to measure the following biochemical biomarkers: $i$ ) the CAT activity was determined by measuring the decomposition of hydrogen peroxide at $240 \mathrm{~nm}\left(37^{\circ} \mathrm{C}, 2 \mathrm{~min}\right)$, using a molar extinction coefficient of $43.6 / \mathrm{M} \mathrm{cm}$. The reaction mixture consisted of $20 \mu \mathrm{L}$ of pure sample, $40 \mu \mathrm{L}$ of $\mathrm{H}_{2} \mathrm{O}_{2}(10 \%, \mathrm{v} / \mathrm{v})$ and $1900 \mu \mathrm{L}$ of PBS $(\mathrm{pH} 7,100 \mathrm{mM})$; ii) the lipid peroxidation was determined by the reaction of thiobarbituric acid-reactive substances (TBARS) according to the method of Buege and Aust (1978), with minor modifications to aquatic vertebrates. The lipid peroxidation in whole fish was determined by measuring the formation of the colour produced during the TBARS reaction. To this end, fish homogenate $(20 \mu \mathrm{L})$ and $380 \mu \mathrm{L}$ of the reaction mixture (trichloroacetic/ thiobarbituric acid) were incubated at $90.0 \pm 0.5^{\circ} \mathrm{C}$ for $15 \mathrm{~min}$; then the coloured product was cooled and centrifuged at $7500 \times \mathrm{g}$ for $8 \mathrm{~min}$. Finally, the absorbance was measured at $530 \mathrm{~nm}$. Lipid peroxidation or TBARS levels were expressed as mmol MDA mg ${ }^{-1}$ protein (Buege et al. 1978); and iii) AChE activity was determined by the method of Ellman (1961). The reaction mixture consisted of $150 \mu \mathrm{L}$ of PBS (100 mM, pH 8), $50 \mu \mathrm{L}$ of acetylthiocholine iodide (1 mM), $150 \mu \mathrm{L}$ of 5,5'-dithiobis-(2-nitrobenzoic acid) $(0.5 \mathrm{mM})$ and $10 \mu \mathrm{L}$ of pure sample. The change in absorbance was recorded at $412 \mathrm{~nm}\left(37^{\circ} \mathrm{C}, 1 \mathrm{~min}\right)$. The enzymatic activity was calculated using a molar extinction coefficient of $14.150 \mathrm{M}^{-1} \mathrm{~cm}^{-1}$. Protein concentration was determined according to the Bradford method (Bradford 1976). All biochemical enzyme reactions and protein determinations were measured using a spectrophotometer (Rayleigh - Model UV2601 UV/VIS Double Beam Spectrophotometer, China).

\subsubsection{Individual endpoints}

Mortality was considered as the lethal endpoint; so, fishes were examined daily, and the mortality criterion was the lack of sudden swimming in response to gentle touching. Dead individuals were fixed in formaldehyde (10\%, v/v). The lethal concentration (LC-50), No Observed Effect Concentration (NOEC), and the Lowest Observed Effect Concentration (LOEC) values were determined in fishes at each exposure time. 
The altered swimming activity in fishes was evaluated by direct observation according to parameters proposed by Little and Finger (1990), characterized by changes in water column position (surfacing, resting on bottom), swimming posture (head-up swimming), body movements (increased or decreased waveform of body movement) or swimming patterns (frequent turns or spiralling), since they often occur during toxicant exposure. Extreme cases such as a loss of coordination, convulsive movements or loss of equilibrium were also considered. The all-or-none occurrence of activity level has been proposed as sublethal biomarkers, and successfully used to describe swimming alterations after the exposure to several environmental stressors (Shuman-Goodier and Propper 2016).

\subsubsection{Integrative response of biomarkers}

To integrate the different results, two methods were reliably performed: i) the Integrated Biomarker Response Index (IBR) was calculated, according to Baudou et al. (2019), considering the following biomarkers: CAT, TBARS, AChE, swimming activity and MNs. The IBR provides a numeric value that integrates all these responses. Higher IBR values indicate higher stress levels (Baudou et al. 2019); ii) the Principal Component Analysis (PCA) was used to determinate the implications of each biomarker at each concentration taken into account in this study. The significance of correlations was examined by simple linear regression and correlation analyses obtained with $\mathrm{R}$ software v.2.11.1. The level of significance was set at $\mathrm{a}=0.05$ for all tests, unless otherwise indicated.

\subsection{Statistical analysis}

The LC-50 values, concentration response curves and ecotoxicological parameters such as slope and correlation coefficient at different sampling times (24 to $96 \mathrm{~h}$ ) with $95 \%$ of confidence limits were estimated, using the U.S. EPA Probit Analysis (Finney 1952) with the package "ecotoxicology" for $R$ software v.2.11.1 (R Core Team 2010, October 14, 2015). All significance test for regression and correlation were performed according to Zar (2010).

The proportion of fishes affected by test chamber was calculated for mortality, swimming activity, CAT, TBARS, AChE and MNs. These parameters were subsequently angular-transformed. ANOVA one-way with Dunnett's test was performed to compare the different test concentrations to the control group, and to obtain NOEC and LOEC values. Homogeneity of variances and normality, for ANOVA assumptions, were corroborated with Barlett's test and $\mathrm{x}^{2}$ test, respectively. When these assumptions could not be met, a nonparametric test was performed (Zar 2010).

\section{Results}

\subsection{Cytogenetical endpoints}


The results revealed that BDE-209 induced an increase in the frequency of MNs in $G$. affinis erythrocytes after $48 \mathrm{~h}(p<0.05)$, see Table 1 . The exposure to BDE-209 showed an acute adverse effect with a significant increase in micronucleus frequencies at sublethal concentrations such as 10, 25 and $50 \mu \mathrm{g} . \mathrm{L}^{-}$ 1 of BDE-209 $(p<0.05)$, in comparison to the negative control group. Likewise, at $48 \mathrm{~h}$, the respective LOEC value was $10 \mu \mathrm{g} . \mathrm{L}^{-1}$ of BDE-209. On the other hand, the BDE-209 did not induce an increment of MNs frequencies in $G$. affinis erythrocytes after 96 h of exposure at sublethal concentrations $(p>0.05)$.

\subsection{Biochemical endpoints: ROS enzymes}

The results in Table 1 indicated that all enzymatic systems were altered after $48 \mathrm{~h}$ of exposure to BDE209 , in comparison to negative control group. Particularly, the following biochemical biomarkers were altered by the action of BDE-209 after acute exposure: the antioxidant response of carbohydrates and lipids measured through CAT and TBARS, respectively; as well as the cholinergic system measured by the response of AChE.

\subsubsection{Catalase activity}

The individuals exposed to 25 and $50 \mu \mathrm{g} \cdot \mathrm{L}^{-1}$ of BDE-209 showed a decrease in the catalase activity after 48 hours of exposure $(p<0.05$, Table 1$)$, with respect to the negative control group. However, no significant differences were observed in the antioxidant response of CAT after $96 \mathrm{~h}$ at the concentrations tested $(p>0.05)$.

\subsubsection{TBARS determinations}

The evaluation of oxidative degradation of lipids or lipid peroxidation in fishes showed that $50 \mu \mathrm{g} \cdot \mathrm{L}^{-1}$ of BDE-209 concentration altered the activity of TBARS by inducing a significant decrease after $48 \mathrm{~h}$ of exposure $(p<0.05$, Table 1$)$, with respect to the negative control group. On the contrary, no significant differences were observed in the response of lipid peroxidation after $96 \mathrm{~h}$ at the concentrations tested, in relation to the negative control group $(p>0.05)$.

\subsubsection{AChE response}

A concentration of 25 and $50 \mu \mathrm{g} . \mathrm{L}^{-1}$ of BDE-209 modified the activity of AChE by increase after $48 \mathrm{~h}$ of exposure respect to negative control group ( $p<0.001$, Table 1). Additionally, an increase in the AChE activity was observed at the lowest concentration of $10 \mu \mathrm{g} . \mathrm{L}^{-1}$ of BDE-209 after $96 \mathrm{~h}$ of exposure, with respect to the negative control group $(p<0.05)$.

\subsection{Individual endpoints}




\subsubsection{Swimming activity}

The analysis of swimming activity in $G$. affinis revealed that a concentration of $50 \mu \mathrm{g} \cdot \mathrm{L}^{-1}$ of BDE-209 induced a significant increase of alterations in this endpoint after $48 \mathrm{~h}$ of exposure $(p<0.001)$, and this trend was observed at $96 \mathrm{~h}(p>0.001)$ with respect to the negative control group.

\subsubsection{Lethal effects}

The LC-50 values were determined by the mortality data obtained after the BDE-209 exposure in fishes, at all times evaluated. With respect to our experiments, no mortality in fishes at the tested concentration of methanol, and in the negative control groups, was observed. The LC-50 values remain constant after all exposure times ( 24 to $96 \mathrm{~h}$ ), and the corresponding value was $27.79 \mu \mathrm{g} . \mathrm{L}^{-1}$ BDE-209 (confidence interval $95 \%=19.68-37.42 \mu \mathrm{g} . \mathrm{L}^{-1}$ BDE-209; $\left.\mathrm{R}^{2}=0.991, p<0.05\right)$ for $G$. affinis. In this case, NOEC and LOEC values were 10 and $25 \mu \mathrm{g} . \mathrm{L}^{-1} \mathrm{BDE}-209$, respectively, at all exposure times.

\subsection{Biomarkers}

\subsubsection{Principal Component Analysis (PCA)}

Biomarkers exhibit a different response when fishes were exposed to BDE-209 (Fig. 1). Two principal components (PC) obtained by the PCA correlations among the response variables, at $48 \mathrm{~h}$ of exposure, explained the $94.9 \%$ of the variability ( $P C 1=70.5 \%, P C 2=24.4 \%$ ). In addition, the reduction of the dimensionalities through the PCA demonstrated a concentration gradient, separating the lowest concentration of BDE-209 $\left(10 \mu \mathrm{g} . \mathrm{L}^{-1}\right)$ from medium and higher concentrations ( 25 and $\left.50 \mu \mathrm{g} . \mathrm{L}^{-1}\right)$. CAT and TBARS activity showed a higher positive correlation $(r=0.78)$ but negative correlations with AChE and MNs which showed positive correlation $(r=0.85)$. It is important to note that CAT and TBARS were negatively correlated with mortality $(r=-0.91)$. In addition, at the lowest concentration $\left(10 \mu \mathrm{g} . \mathrm{L}^{-1}\right)$, only antioxidant biomarkers showed a response; while at a medium concentration $\left(25 \mu \mathrm{g} . \mathrm{L}^{-1}\right)$, the response was given by AChE and MNs. Finally, at the highest concentrations assayed (50 and $100 \mu \mathrm{g} \cdot \mathrm{L}^{-1}$ ), the mortality was the prevalent effect. Furthermore, a gradient of adverse effects related to an increase in BDE-209 concentration can be observed. On the other hand, the analysis of PCA was not possible to obtain at $96 \mathrm{~h}$ because AChE was the only biomarker to respond.

\subsubsection{Integrated Biomarker Response}

Figure 2 depicts IBR for each enzyme studied; it includes the scores of each parameter and each sampling time during the exposure. Better scores of IBR are according to healthier organisms whilst worse scores represent more stressed organisms. The analysis of the IBR values showed, in general, 
better scores for control group values with respect to the fish exposures to BDE-209 after $48 \mathrm{~h}$. Control values presented better values or healthier values (IBR $=11.62)$ according to biomarkers responses. On the contrary, at concentration of $25 \mu \mathrm{g} . \mathrm{L}^{-1}$ of BDE-209 was observed stressed organism with values of $\mathrm{IBR}=9.83$. Additionally, the values among 10 and $25 \mu \mathrm{g} \cdot \mathrm{L}^{-1}$ of BDE-209 increase AChE, while catalase values decrease. However, the IBR value for $10 \mu \mathrm{g} \cdot \mathrm{L}^{-1}$ was equal to 12.01 showing unstressed organisms despite the increase of AChE. Finally, the star plot shows a greater stress at concentration of $50 \mu \mathrm{g} \cdot \mathrm{L}^{-1}$ of BDE-209, evidenced by the increase in the TBARS response.

\section{Discussion}

Our studies show that these emerging pollutants, specifically the flame retardant BDE-209, produce toxicity at different levels, up to death, in a bioindicator fish such as $G$. affinis. Moreover, few studies are reported the LC-50 values for non-vertebrate aquatic organisms (Davies and Zou 2012; Zhang et al. 2013; Xiong et al. 2018). Particularly, the efective concentration (EC-50), similar to LC-50, was reported for the algae Heterosigma akashiwo and Karenia mikimotoi with values around 22.58 and $120.8 \mu \mathrm{g} . \mathrm{L}^{-1} \mathrm{BDE}-$ 209, respectively (Zhang et al. 2013) Furthermore, in Daphnia magna it was not possible to obtain LC-50 values after 48 hours for exposed to a range between 0.3-500 $\mu \mathrm{g} . \mathrm{L}^{-1}$ (Davies and Zou 2012). However, Xiong et al. (2018) reported that a mixture containing $125 \mu \mathrm{g} . \mathrm{L}^{-1}$ (acute exposure) and $25 \mu \mathrm{g} . \mathrm{L}^{-1}$ of BDE209 (chronic exposure) induces $50 \%$ of immobility (IC-50). Finally, the only mortality report has been in zebrafish (Danio rerio) when exposed to $300 \mu \mathrm{g} . \mathrm{L}^{-1}$ for $96 \mathrm{~h}$, although no LC-50 value was reported (Han et al. 2017). In this context, this work shows the first LC-50 value for an aquatic vertebrate after acute exposure to BDE-209, resulting in a relatively high sensitivity value for the species tested. Similar LC-50 values have been estimated for other PBDE congeners in D. rerio embryos such as 250, 350, 520 and 840 $\mu \mathrm{g} \mathrm{L} \mathrm{L}^{-1}$ for BDE-28, BDE-47, BDE-99 and BDE-100, respectively (Usenko et al. 2011).

In addition, this work shows the sublethal effects of BDE-209 separately, using the biomarkers as early warning signals during the first 48 hours of exposure to BDE-209. Specifically, an increase in cytotoxic and genotoxic effects was observed with increased frequency of MNs at all concentrations, tested at 48 h. These results are consistent with those of Jin et al. (2010) which showed BDE-209 as cytotoxic and genotoxic for rainbow trout cell lines; since it produces apoptosis, metabolic activity alterations (MTT assay) and increase of ROS species.

According to Jin et al. (2010), BDE-209 generates ROS species in O. mykiss, and we can confirm this assumption because it is corroborated by the alteration of enzymes linked to oxidative stress such as CAT and TBARS. Specifically, in this work, the response observed in CAT activity against BDE-209 is consistent with that observed by Xie et al. (2014), where Carassius auratus was exposed for $96 \mathrm{~h}$ at concentrations between 1 to $5 \mu \mathrm{g} \cdot \mathrm{L}^{-1}$ of BDE-209. Moreover, the inhibition of antioxidant enzymes, such as CAT and TBARS, was due to the loss of the function of the antioxidant system in scavenging overproduced ROS (Xie et al. 2014). Also, previous reports indicate that the decrease of enzyme activity could reflect that there is not a defence system response and antioxidant mechanisms to eliminate the 
highly reactive xenobiotics produced in cells. This situation could be considered as a non-adaptive response to counteract the ROS generation (Rautenberg et al. 2015; Touaylia and Labiadh 2019) caused by these emerging contaminants.

The analysis of the effect of lipid peroxidation showed a marked inhibition of TBARS only at the highest sublethal concentration tested (50 $\mu \mathrm{g} \cdot \mathrm{L}^{-1}$ of BDE-209). In this regard, our results are not in accordance with Zhu et al. (2016) who reported an increase of TBARS after the exposure of zebrafish to BDE-209 as a protective response. Probably, as proposed by Touaylia and Labiadh (2019) the poly-unsaturated fatty acids are the target of attack by the hydroxyl radical capable of extracting hydrogen from the carbons located between two double bonds to form a ROS. This reaction, known as lipid peroxidation, acts as a chain reaction because the formed peroxyl radical converts to peroxide in contact with another fatty acid forming, in this case, a new ROS (Esterbauer et al. 1992; Touaylia and Labiadh 2019). In addition, the peroxyl radical can release several toxic aldehydes including MDA or hydroxynonenal (Touaylia and Labiadh 2019).

In summary, the biochemical analysis of some antioxidant systems indicates that BDE-209 can decrease and/or inhibit systems that act against free radicals in fishes such as G. affinis. In this respect, and according to Touaylia and Labiadh (2019), it is important to note that the recorded adverse effects in the antioxidant system are related to two factors: the toxicity of the environmental stressor, and the sensitivity of the target species. Some environmental stressors such as BDE-209 may lead to an excessive stimulation of the cholinergic system (Wang et al. 2018). In particular, the environmental stressors can interfere with its catalytic process based on their structural similarity to AChE (Xie et al. 2014; Wang et al. 2018; Touaylia and Labiadh 2019) which affects the swimming activity by tremors, convulsions, and erratic or lethargic swimming (Xie et al. 2014; Zhu et al. 2016), as observed in this study. Furthermore, if $\mathrm{AChE}$ is inhibited by these emergent pollutants, the neurotransmitter (e.g. acetylcholine) would be accumulated in the synaptic space leading to muscle tetany and death (Wang et al. 2018). This type of response of AChE has already been observed in $G$. affinis exposed to other environmental stressors as reported by Rao et al. (2005), who relate AChE alterations to locomotor and behavioural problems in the mosquitofish. Finally, our results corroborate that this polybrominate induces neurotoxicity in $G$. affinis. Besides, we believe that the AChE determination resulted in an excellent biomarker to evaluate the effects produced by BDE-209.

In recent years, Newman (2014) highlighted the importance of evaluating the correlation of biomarkers as a whole and not separately. This information helps to understand not only the susceptibility of organisms to environmental stressors but also their mode of action and toxicity, which can later be used as early warning signals in environments that are disturbed or contaminated by the presence of environmental stressors as we highlight in our studies in this regard (Pérez-Iglesias et al. 2020). Furthermore, these results show that the endpoints evaluated respond to the concept of biomarkers proposed by Walker et al. (2009) who affirms that the analyzed endpoints are useful biomarkers to use. Specifically, this study shows that the adverse effects of BDE-209 induce alterations in the physiological responses evidenced when evaluating biomarkers at different levels of biological organization with a progression of effects 
from the cellular to the individual level that ends in death. In conclusion, and in agreement with other authors (Van der Oost et al., 2003; Newman, 2014), we recommend the use of this type of approach for ecotoxicological studies since it allows us to discern the groups of anurans that were exposed to environmental stressors from those that were not exposed, as seen in the IBR results. In this sense, the ecotoxicological information that evaluates the correlation of adverse effects at different levels of biological organization is scarce and this work makes an important contribution at this point since it allows to generate a novel information not provided by the individual and separate analysis of each biomarker.

\section{Conclusion}

This work has shown that the species $G$. affinis constitutes a good model organism for this type of toxicological evaluations, and it can be used as a bioindicator. In addition, the biomarkers studied provide an integrated response to environmental stressors such as BDE-209, and an early detection of the sublethal effects of emerging pollutants such as flame retardants. This situation highlights the importance of these biomarkers at higher levels of organization. However, further studies should be carried out in order to deepen this research work, complementing it with locomotor, behavioural and swimming effects on this species and to evaluate the effects of these emerging pollutants on the Neotropical biota, due to their constant growth and the danger they pose to aquatic ecosystems.

\section{Declarations}

\section{Acknowledgements}

Authors thank Instituto de Química de San Luis “Dr. Roberto Olsina”- Consejo Nacional de Investigaciones Científicas y Tecnológicas (INQUISAL-CONICET), and Universidad Nacional de San Luis (Project PROICO 2-1914) for their financial support; as well as Lidia Unger for the proofreading and editing of the manuscript.

\section{Ethical Approval}

Not applicable

\section{Consent to Participate}

The authors has consented to the submission

\section{Consent to Publish}


The authors gives their consent for the publication of identifiable details, which can include photograph(s) and/or videos and/or case history and/or details within the text to be published in the above Journal and Article.

\section{Availability of data and materials}

Not applicable

\section{Competing interests}

The authors declare that they have no competing interests

\section{Funding}

This study was funded by Postdoctoral Internal Scholarships Granting Institution: National Commission for Scientific and Technical Research (CONICET). File No. 004121/17, Research Project at the National University of San Luis "Environmental quality of aquatic ecosystems: analytical methodologies for the determination of compounds of environmental interest. Line 2: Development and validation of sensitive and selective analytical methodologies for the determination of compounds of environmental interest" (UNSL-Ord. CS No 64/15) and funds from Research Project "Assessment of the quality and toxicological risk of water and soils, contaminated with analyts from electronic waste using native bioindicators from semiarid regions" National Agency for Scientific and Technological Promotion, FONCYT. Innovative Argentina - Youth. (PICT-2018-01067 Res. 401-19).

\section{Authors' contributions}

Pérez-lglesias, JM: wrote the paper, conceived and designed the experimentation, collect and data analysis and funds; González, P.: revison of the paper and funds of experimental, Calderón MR: redaction and idiomatic correction of the paper; Natale, GS.: conceived and designed the experimentation, Almeida, $\mathrm{CA}$ : wrote the paper, conceived and designed the experimentation, data analysis and funds for experimentation.

\section{References}

1. Abbasi G, Buser AM, Soehl A, Murray MW, Diamond, ML (2015) Stocks and flows of PBDEs in products from use to waste in the US and Canada from 1970 to 2020. Environmental Science \& Technology 49(3):1521-1528.

2. Adams SM, Ham KD (2011) Application of biochemical and physiological indicators for assessing recovery of fish populations in a disturbed stream. Environmental Management 47:1047-1063. 
3. Anacleto P, Figueiredo C, Baptista M, Maulvault AL, Camacho C, Pousão-Ferreira P, Valente LM, Marques A, Rosa R (2018) Fish energy budget under ocean warming and flame retardant exposure. Environmental Research 164:186-196.

4. Barón E, Gago-Ferrero P, Gorga M, Rudolph I, Mendoza G, Zapata AM, Díaz-Cruz S, Barra R, OcampoDuque W, Páez M (2013) Occurrence of hydrophobic organic pollutants (BFRs and UV-filters) in sediments from South America. Chemosphere 92:309-316.

5. Baudou FG, Ossana NA, Castañé PM, Mastrángelo MM, Núñez AAG, Palacio MJ, Ferrari L (2019) Use of integrated biomarker indexes for assessing the impact of receiving waters on a native neotropical teleost fish. Science of The Total Environment 650:1779-1786.

6. Beliaeff B, Burgeot T (2002) Integrated biomarker response: a useful tool for ecological risk assessment. Environmental Toxicology and Chemistry 21:1316-1322.

7. Bradford MM (1976) A rapid and sensitive method for the quantitation of microgram quantities of protein utilizing the principle of protein-dye binding. Analytical Biochemistry 72:248-254.

8. Brodeur JC, Sanchez M, Castro L, Rojas DE, Cristos D, Damonte MJ, Poliserpi MB, D'Andrea MF, Andriulo AE (2017) Accumulation of current-use pesticides, cholinesterase inhibition and reduced body condition in juvenile one-sided livebearer fish (Jenynsia multidentata) from the agricultural Pampa region of Argentina. Chemosphere 185:36-46.

9. Buege JA, Aust SD (1978) Microsomal lipid peroxidation. In: Methods in enzymology:302-310 pp.

10. Cabrera MB, Bogan S, Posadas P, Somoza GM, Montoya-Burgos JI, Cardoso YP (2017) Risks associated with introduction of poeciliids for control of mosquito larvae: first record of the non-native Gambusia holbrooki in Argentina. Journal of Fish Biology 91:704-710.

11. Chen L, Zhu B, Guo Y, Xu T, Lee JS, Qian PY, Zhou B. 2016. High-throughput transcriptome sequencing reveals the combined effects of key e-waste contaminants, decabromodiphenyl ether (BDE-209) and lead, in zebrafish larvae. Environmental Pollution 214:324-333.

12. Cordero AB, Díaz JC, García AG (2004) Los retardantes de flama polibromados: ¿nuevas sustancias de prioridad ambiental?. Gaceta Ecológica:45-52.

13. Dang HM, Inagaki Y, Yamauchi Y, Kurihara T, Vo CH, Sakakibara Y (2017) Acute exposure to 17Aethinylestradiol alters aggressive behavior of mosquitofish (Gambusia affinis) toward Japanese medaka (Oryzias latipes). Bulletin of Environmental Contamination and Toxicology 98:643-648.

14. Davies R, Zou E (2012) Polybrominated diphenyl ethers disrupt molting in neonatal Daphnia magna. Ecotoxicology 21(5):1371-1380.

15. Díez-del-Molino D, García-Berthou E, Araguas RM, Alcaraz C, Vidal O, Sanz N, García-Marín JL (2018) Effects of water pollution and river fragmentation on population genetic structure of invasive mosquitofish. Science of the Total Environment 637:1372-1382.

16. European Food Safety Authority (2011) EFSA Panel on Contaminants in the Food Chain (CONTAM). Scientific opinion on polybrominated diphenyl ethers (PBDEs) in food. EFSA Journal 9: 2156.

17. Eljarrat E, Barceló D (2018) How do measured PBDE and HCBD levels in river fish compare to the European Environmental Quality Standards?. Environmental Research 160:203-211. 
18. Ellman GL, Courtney KD, Andres Jr V, Featherstone RM (1961) A new and rapid colorimetric determination of acetylcholinesterase activity. Biochemical Pharmacology 7:88-95.

19. Espinosa Ruiz C, Manuguerra S, Cuesta A, Santulli A, Messina CM (2019) Oxidative stress, induced by sub-lethal doses of BDE 209, promotes energy management and cell cycle modulation in the marine fish cell line SAF-1. International Journal of Environmental Research and Public Health $16: 474$.

20. Esterbauer H, Gebicki J, Puhl H, Jürgens G (1992) The role of lipid peroxidation and antioxidants in oxidative modification of LDL. Free Radical Biology and Medicine 13:341-390.

21. Fenech M (2007) Cytokinesis-block micronucleus cytome assay. Nature Protocols 2:1084.

22. Finney DJ (1952) Probit analysis: a statistical treatment of the sigmoid response curve. Cambridge University press.

23. François A, Verreault $J$ (2018) Interaction between deca-BDE and hepatic deiodinase in a highly PBDE-exposed bird. Environmental Research 163:108-114.

24. Garcia-Reyero N, Escalon BL, Prats E, Stanley JK, Thienpont B, Melby NL, Barón E, Eljarrat E, Barceló D, Mestres J (2014) Effects of BDE-209 contaminated sediments on zebrafish development and potential implications to human health. Environment International 63:216-223.

25. Goodman, JE (2009) Neurodevelopmental effects of decabromodiphenyl ether (BDE-209) and implications for the reference dose. Regulatory Toxicology and Pharmacology 54(1):91-104.

26. Hamza-Chaffai A (2014) Usefulness of bioindicators and biomarkers in pollution biomonitoring. International Journal of Biotechnology for Wellness Industries 3:19-26.

27. Han Z, Li Y, Zhang S, Song N, Xu H, Dang Y, Liu C, Giesy JP, Yu H (2017) Prenatal transfer of decabromodiphenyl ether (BDE-209) results in disruption of the thyroid system and developmental toxicity in zebrafish offspring. Aquatic Toxicology 190:46-52.

28. He J, Yang D, Wang C, Liu W, Liao J, Xu T, Bai C, Chen C, Lin K, Huang C (2011) Chronic zebrafish low dose decabrominated diphenyl ether (BDE-209) exposure affected parental gonad development and locomotion in F1 offspring. Ecotoxicology 20:1813-1822.

29. Hou L, Yang Y, Shu H, Ying G, Zhao J, Fang G, Xin L, Shi W, Yao L, Cheng X (2018) Masculinization and reproductive effects in western mosquitofish (Gambusia affinis) after long-term exposure to androstenedione. Ecotoxicology and Environmental Safety 147:509-515.

30. Hu GC, Dai JY, Xu ZC, Luo XJ, Cao H, Wang JS, et al. (2010) Bioaccumulation behavior of polybrominated diphenyl ethers (PBDEs) in the freshwater food chain of Baiyangdian Lake, North China. Environment International 36(4):309-315.

31. Jin S, Yang F, Hui Y, Xu Y, Lu Y, Liu J (2010) Cytotoxicity and apoptosis induction on RTG-2 cells of 2, 2', 4, 4'-tetrabromodiphenyl ether (BDE-47) and decabrominated diphenyl ether (BDE-209). Toxicology in Vitro 24:1190-1196.

32. Kaviraj A, Bhunia F, Saha FC (2004) Toxicity of methanol to fish, crustacean, oligochaete worm, and aquatic ecosystem. International Journal of Toxicology 23:55-63. 
33. Kuo Y, Sepúlveda MS, Hua I, Ochoa-Acuña HG, Sutton TM. 2010. Bioaccumulation and biomagnification of polybrominated diphenyl ethers in a food web of Lake Michigan. Ecotoxicology 19:623-634.

34. Labandeira A, Eljarrat E, Barceló D (2007) Congener distribution of polybrominated diphenyl ethers in feral carp (Cyprinus carpio) from the Llobregat River, Spain. Environmental Pollution 146(1):188-195.

35. La Guardia MJ, Hale RC, Harvey E (2007) Evidence of debromination of decabromodiphenyl ether (BDE-209) in biota from a wastewater receiving stream. Environmental Science \& Technology 41:6663-6670.

36. Lana NB, Fontana AR, Ciocco NF, Altamirano JC (2010) Determination of polybrominated diphenyl ethers in water samples from Mendoza River Basin by HS-SPME-GC-MS/MS. Revista de la Facultad de Ciencias Agrarias 42(2): 85-98.

37. Larramendy ML (2017) Ecotoxicology and Genotoxicology: Non-traditional Terrestrial Models. Royal Society of Chemistry.

38. Lee CC, Hsieh CY, Chen CS, Tien CJ (2020) Emergent contaminants in sediments and fishes from the Tamsui River (Taiwan): Their spatial-temporal distribution and risk to aquatic ecosystems and human health. Environmental Pollution 258:113733.

39. Li W, Zhu L, Zha J, Wang Z (2014) Effects of decabromodiphenyl ether (BDE-209) on mRNA transcription of thyroid hormone pathway and spermatogenesis associated genes in Chinese rare minnow (Gobiocypris rarus). Environmental Toxicology 29:1-9.

40. Little EE, Finger SE (1990) Swimming behavior as an indicator of sublethal toxicity in fish. Environmental Toxicology and Chemistry 9:13-19.

41. Liu Y, Luo XJ, Huang LQ, Tao L, Zeng YH, Mai, BX (2018) Halogenated organic pollutants in aquatic, amphibious, and terrestrial organisms from an e-waste site: Habitat-dependent accumulation and maternal transfer in watersnake. Environmental Pollution 241:1063-1070.

42. Mackintosh SA, Wallace JS, Gross MS, Navarro DD, Pérez-Fuentetaja A, Alaee M, Aga DS (2015) Review on the occurrence and profiles of polybrominated diphenyl ethers in the Philippines. Environment International 85:314-326.

43. McGrath TJ, Ball AS, Clarke B0 (2017) Critical review of soil contamination by polybrominated diphenyl ethers (PBDEs) and novel brominated flame retardants (NBFRs); concentrations, sources and congener profiles. Environmental Pollution 230:741-757.

44. Miglioranza KS, Gonzalez M, Ondarza PM, Shimabukuro VM, Isla FI, Fillmann G, et al. (2013) Assessment of Argentinean Patagonia pollution: PBDEs, OCPs and PCBs in different matrices from the Río Negro basin. Science of the Total Environment 452:275-285.

45. Newman MC (2014) Fundamentals of Ecotoxicology: The Science of Pollution. CRC press.

46. Noyes PD, Hinton DE, Stapleton HM (2011) Accumulation and debromination of decabromodiphenyl ether (BDE-209) in juvenile fathead minnows (Pimephales promelas) induces thyroid disruption and liver alterations. Toxicological Sciences 122(2):265-274. 
47. Ondarza PM, Gonzalez M, Fillmann G, Miglioranza KS (2011). Polybrominated diphenyl ethers and organochlorine compound levels in brown trout (Salmo trutta) from Andean Patagonia, Argentina. Chemosphere 83(11):1597-1602.

48. Peng X, Tang C, Yu Y, Tan J, Huang Q, Wu J,Chen S, Mai B (2009) Concentrations, transport, fate, and releases of polybrominated diphenyl ethers in sewage treatment plants in the Pearl River Delta, South China. Environment International 35:303-309.

49. Pérez-Iglesias JM, Brodeur JC, Larramendy ML (2020) An imazethapyr-based herbicide formulation induces genotoxic, biochemical, and individual organizational effects in Leptodactylus latinasus tadpoles (Anura: Leptodactylidae). Environmental Science and Pollution Research 27(2):2131-2143.

50. Ross PS, Couillard CM, Ikonomou MG, Johannessen SC, Lebeuf M, Macdonald RW, Tomy GT (2009) Large and growing environmental reservoirs of Deca-BDE present an emerging health risk for fish and marine mammals. Marine Pollution Bulletin 58(1): 7-10.

51. Tombesi N, Pozo K, Alvarez M, Přibylová P, Kukučka P, Audy O, Klánová J (2017) Tracking polychlorinated biphenyls (PCBs) and polybrominated diphenyl ethers (PBDEs) in sediments and soils from the southwest of Buenos Aires Province, Argentina (South eastern part of the GRULAC region). Science of the Total Environment 575:1470-1476.

52. Tomy GT, Palace VP, Halldorson T, Braekevelt E, Danell R, Wautier K, et al. (2004) Bioaccumulation, biotransformation, and biochemical effects of brominated diphenyl ethers in juvenile lake trout (Salvelinusnamaycush). Environmental Science \& Technology 38(5):1496-1504.

53. Touaylia S, Labiadh H (2019) Effect of the exposure to Mn-doped ZnS nanoparticles on biomarkers in the freshwater western mosquitofish Gambusia affinis, International Journal of Environmental Health Research 29:60-70.

54. United States Environmental Protection Agency - USEPA (2002) Methods for Measuring the Acute Toxicity of Effluents and Receiving Waters to Freshwater and Marine Organisms. $5^{\text {th }}$ Edition.

55. Paniagua-Michel J, Olmos-Soto J (2016) Modern approaches into biochemical and molecular biomarkers: key roles in environmental biotechnology. J Biotechnol Biomater 2(1):100216.

56. Rao JV, Begum G, Sridhar V, Reddy NC (2005) Sublethal efects of monocrotophos on locomotor behavior and gill architecture of the mosquito fish, Gambusia affinis. Journal of Environmental Science and Health 40:813-825.

57. Rautenberg GE, Amé MV, Monferrán MV, Bonansea RI, Hued AC (2015) A multi-level approach using Gambusia affinis as a bioindicator of environmental pollution in the middle-lower basin of Suquía River. Ecological Indicators 48: 706-720.

58. Santín G, Barón E, Eljarrat E, Barceló D (2013) Emerging and historical halogenated flame retardants in fish samples from Iberian rivers. Journal of Hazardous Materials 263:116-121.

59. Shuman-Goodier ME, Propper CR (2016) A meta-analysis synthesizing the effects of pesticides on swim speed and activity of aquatic vertebrates. Science of the Total Environment 565:758-766.

60. Ueno D, Kajiwara N, Tanaka H, Subramanian A, Fillmann G, Lam PKS, Zheng GJ, Muchitar M, Razak H, Prudente M (2004) Global pollution monitoring of polybrominated diphenyl ethers using skipjack 
tuna as a bioindicator. Environmental Science \& Technology 38:2312-2316.

61. Usenko CY, Robinson EM, Usenko S, Brooks BW, Bruce ED (2011) PBDE developmental effects on embryonic zebrafish. Environmental Toxicology and Chemistry 30(8):1865-1872.

62. van der Oost R, Beyer J, Vermeulen NP (2003) Fish bioaccumulation and biomarkers in environmental risk assessment: a review. Environmental Toxicology and Pharmacology 13(2):57149.

63. Vera-Candioti J, Soloneski S, Larramendy ML (2010) Genotoxic and cytotoxic effects of the formulated insecticide Aficida ${ }^{\circledR}$ on Cnesterodon decemmaculatus (Jenyns, 1842)(Pisces: Poeciliidae). Mutation Research 703:180-186.

64. Wang J, Lin Z, Lin K, Wang C, Zhang W, Cui C, Lin J, Dong Q, Huang C (2011) Polybrominated diphenyl ethers in water, sediment, soil, and biological samples from different industrial areas in Zhejiang, China. Journal of Hazardous Materials 197:211-219.

65. Wang S, Wu C, Liu Z, You H (2018) Studies on the interaction of BDE-47 and BDE-209 with acetylcholinesterase (AChE) based on the neurotoxicity through fluorescence, UV-vis spectra, and molecular docking. Toxicology Letters 287:42-48.

66. Wu MH, Tang L, Xu G, Ma J, Liu N, Wang L, Lei JQ (2013) Polybrominated diphenyl ethers in surface sediments from principal watersheds of Shanghai, China: levels, distribution, influencing factors, and risk assessment. Environmental Science and Pollution Research 20:2651-2660.

67. Xie Z, Lu G, Qi P (2014) Effects of BDE-209 and its mixtures with BDE-47 and BDE-99 on multiple biomarkers in Carassius auratus. Environmental Toxicology and Pharmacology 38:554-561.

68. Xiong Q, Shi Y, Lu Y, Pan K, Dakhil MA, Zhang L, Xiao Y (2018) Sublethal or not? Responses of multiple biomarkers in Daphnia magna to single and joint effects of BDE-47 and BDE-209. Ecotoxicology and Environmental Safety 164:164-171.

69. Yu L, Han Z, Liu C (2015) A review on the effects of PBDEs on thyroid and reproduction systems in fish. General and Comparative Endocrinology 219:64-73.

70. Zar JH (2010) Biostatistical Analysis, Prentice Hall.

71. Zhang X, Tang X, Zhou B, Wang Y (2013) Effects of decabromodiphenyl ether (BDE-209) on interspecific competition between two species of marine bloom-forming microalgae. PloS one 8:e56084.

72. Zhao A, Liu H, Zhang A, Wang X, Zhang H, Wang H (2011) Effect of BDE-209 on glutathione system in Carassius auratus. Environmental Toxicology and Pharmacology 32:35-39.

73. Zhu B, Wang Q, Shi X, Guo Y, Xu T, Zhou B (2016) Effect of combined exposure to lead and decabromodiphenyl ether on neurodevelopment of zebrafish larvae. Chemosphere 144:1646-1654.

\section{Table}

Due to technical limitations, table 1 is only available as a download in the Supplemental Files section.

\section{Figures}




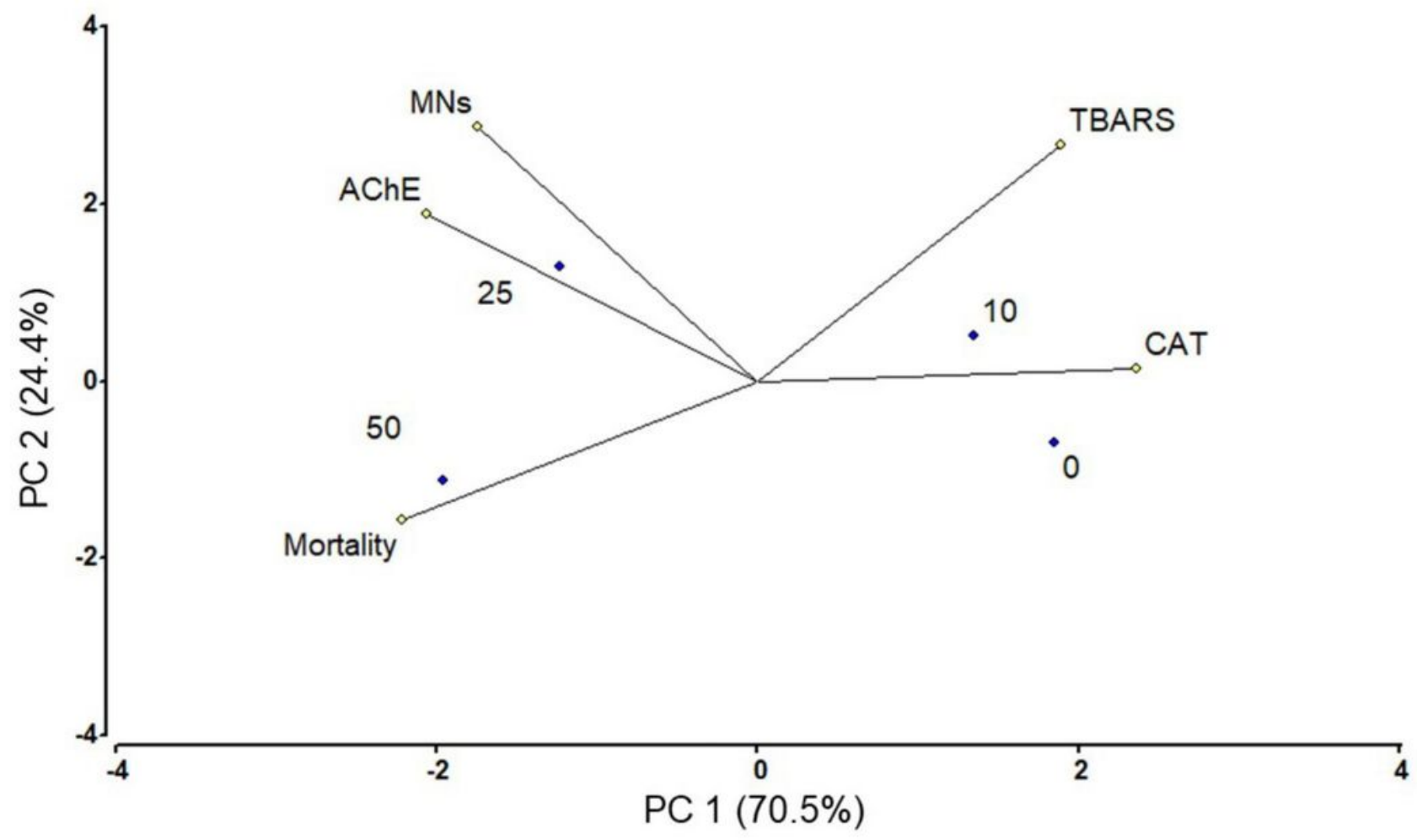

Figure 1

Principal components analysis (PCA) on biomarkers responses at the sublethal exposure in mosquitofish to BDE-209. Values next to points represent the concentration of BDE-209 expressed in $\mu$ g.L-1. 


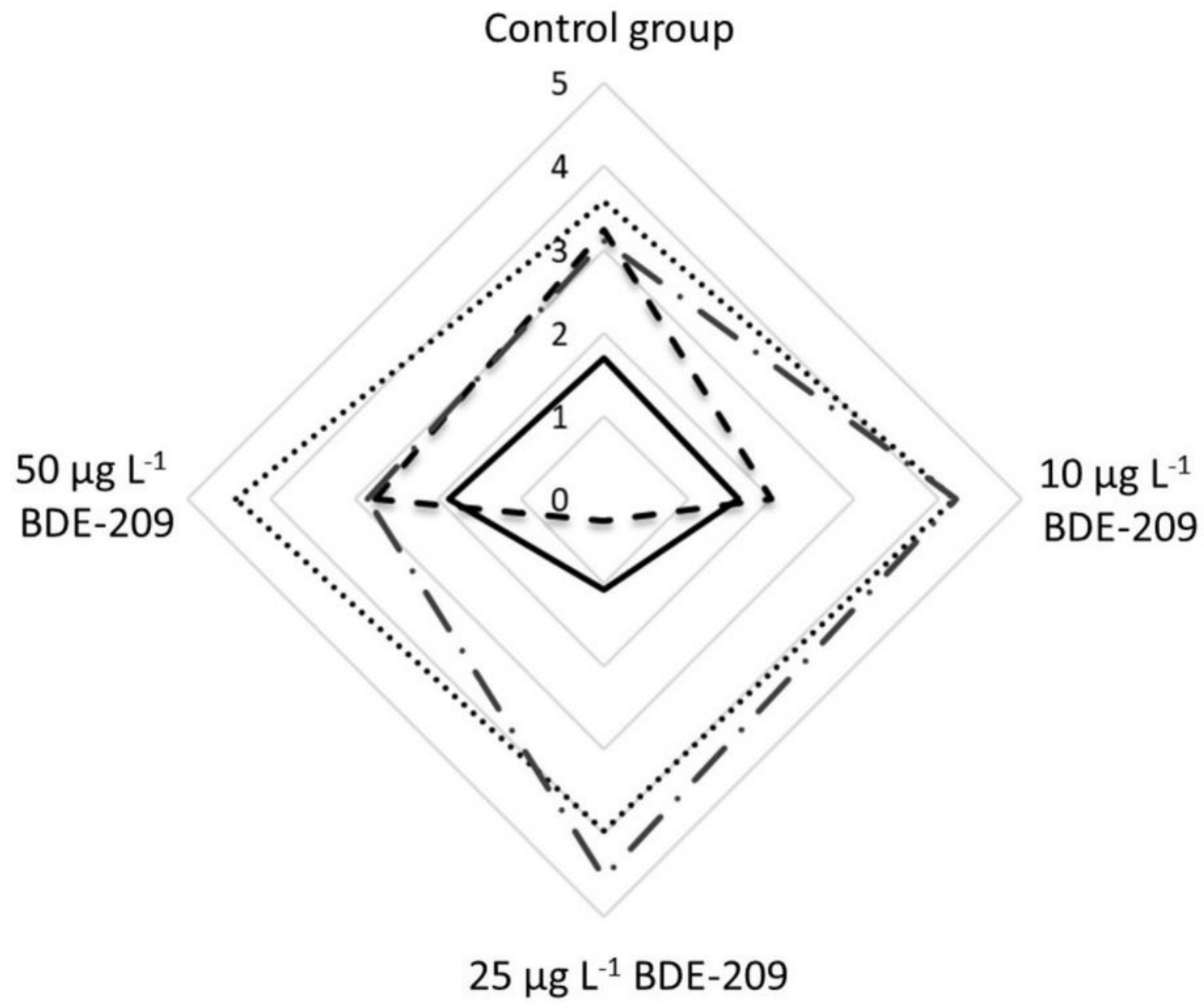

Figure 2

Integrated biomarker response (IBR) and enzymatic response star plots for different concentration of

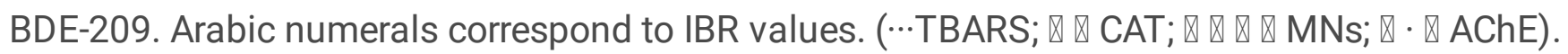

\section{Supplementary Files}

This is a list of supplementary files associated with this preprint. Click to download.

- Table1PerezlglesiasetalESPR.pdf 